\title{
Mental Health Literacy in Cancer Outpatients in Singapore
}

\author{
SH Poon, FQ Wang, J Goh, YH Chan, L Lim
}

\begin{abstract}
Objective: We aimed to evaluate the prevalence of depressive and anxiety symptoms and mental health literacy (MHL) in outpatients with or without cancer in Singapore.

Methods: Oncology outpatients and outpatients without cancer (controls) were assessed for severity of anxiety and depressive symptoms (using the Hospital Anxiety and Depression Scale) and MHL regarding major depressive disorder and generalised anxiety disorder in terms of diagnosis, aetiology, treatment, and attitudes toward mental health services.

Results: A total of 89 oncology outpatients and 61 controls were recruited. Those with primary and secondary education had significantly lower MHL scores than those with university education $(\mathrm{p}=$ $0.001)$. Oncology outpatients and controls were comparable in terms of anxiety $(13.5 \%$ vs $9.8 \%, p=0.5)$, depression $(2.2 \%$ vs $1.6 \%, p>0.99)$, and total MHL score (7.94 vs 9.13, $\mathrm{p}=0.102)$.

Conclusions: MHL is comparable between oncology outpatients and controls and is positively associated with education level.
\end{abstract}

Key words: Anxiety; Depression; Health literacy; Neoplasms

Shi Hui Poon, MBBS, MRCPsych (UK), FAMS, Department of Psychiatry, Singapore General Hospital, Singapore

Fu Qiang Wang, MBBS, MRCP (UK), MMed (Int Med), FRCR (Clinical Oncology), Department of Radiation Oncology, National Cancer Centre Singapore, Singapore

Justine Goh, BSocSci, Department of Psychiatry, Singapore General Hospital, Singapore

Yiong Huak Chan, PhD, Biostatistics Unit, Yong Loo Lin School of Medicine, National University of Singapore, National University Health System, Singapore Leslie Lim, [MBBS, MRCPsych, FRCPsych, FAMS], Department of Psychiatry, Singapore General Hospital, Singapore

Address for correspondence: Dr Shi Hui Poon, Department of Psychiatry, Singapore General Hospital, Outram Road, Singapore 169608.

Email:poon.shi.hui@singhealth.com.sg

Submitted: 20 February 2018; Accepted: 3 August 2018

\section{Introduction}

A diagnosis of cancer often gives rise to psychological distress, which may develop into severe psychiatric problems if not identified and treated adequately. A Taiwanese study reported that $22 \%$ of patients with cancer suffered from psychological distress, including adjustment disorder (39\%), major depressive disorder (33.9\%), and anxiety disorder (7\%). ${ }^{1}$ The prevalence of depression and anxiety among patients with cancer has been reported to be $20 \%$ to $38 \%{ }^{2,3}$ In Singapore, the prevalence of major depressive disorder and generalised anxiety disorder among patients with cancer have been reported to be $16.8 \%$ and $9.5 \%$, respectively -10 times higher than the corresponding rates among the general population. ${ }^{4}$ However, correct identification and referral for treatment of patients with cancer and mental illness remain low., In Singapore, only $32 \%$ of patients with mental illness were receiving psychiatric treatment; this may indicate barriers preventing them from seeking treatment. ${ }^{7}$

Lower mental health service utilisation has been reported to be associated with lower education level and mental health literacy (MHL) but not with household income. ${ }^{8}$ MHL refers to the understanding of and ability to identify mental disorders, their aetiology, knowledge of how and where to seek mental health-related help, and management and prevention of mental health disorders. ${ }^{9}$ Poor MHL negatively impacts help seeking and treatment decisions ${ }^{10-14}$ and is associated with worse cancer prognosis, quality of life, and treatment adherence. ${ }^{15,16}$

There is a paucity of studies examining MHL of patients with cancer. The present study aimed to compare outpatients with or without cancer in terms of the prevalence of depressive and anxiety symptoms and MHL. We hypothesised that higher education was predictive of higher MHL and that cancer outpatients who sought psychiatric services would have higher MHL than controls.

\section{Material and methods}

This study was approved by the SingHealth Combined Institutional Review Board. Written informed consent was obtained from each participant before the study. Oncology outpatients who underwent radiotherapy at the Department of Radiation Oncology, National Cancer Centre Singapore between November 2014 and September 2015 were interviewed by a research coordinator to ascertain suitability for enrolment. Eligible participants were those aged 21 to 
75 years, conversant in English or Mandarin, and having Eastern Cooperative Oncology Group Performance Status of 0 or $1 .{ }^{17}$ Controls were patients at specialist outpatient clinics of the Singapore General Hospital who had no cancer or psychiatric diagnosis. Patients with delirium, dementia, or a past psychiatric history were excluded.

Severity of anxiety and depressive symptoms was assessed using the Hospital Anxiety and Depression Scale, ${ }^{18}$ which is a 14-item self-report questionnaire on a 4-point Likert scale that assesses a spectrum of depressive and anxiety symptoms in the past week. It has been validated in the Singaporean population. ${ }^{19}$

Two clinical vignettes based on symptoms of major depressive disorder and generalised anxiety disorder derived from the DSM-IV in the absence of a cancer diagnosis were shown to the participants. Their opinions regarding the diagnosis, aetiology, and treatment of the two mental conditions and their attitudes towards mental health services were evaluated using structured questionnaires. Participants were asked to choose the most appropriate answer from a list of predetermined descriptors. The MHL assessment was derived from previously used standards ${ }^{20}$ and adapted to be culturally relevant to local practices. One point was awarded for each correct answer, with no deduction for incorrect answers; the total maximum score is 22 (Table 1).

Data were analysed with SAS version 9.4 (SAS Institute, Cary [NC], USA). The two groups were compared in terms of demographics and levels of depressive and anxiety symptoms. Differences in MHL scores were assessed using the Wilcoxon signed rank test, with the $p$ value derived from matched-pairs analysis based on sex and age. A 2 -sided $\mathrm{p}$ value of $<0.05$ was considered statistically significant.

\section{Results}

A total of 89 oncology outpatients and 61 controls were recruited (Table 2). The oncology outpatients were significantly older than the controls (51.9 vs 44.8 years,

Table 1. Mental health literacy.

\begin{tabular}{|lc|}
\hline Item & $\begin{array}{c}\text { Maximum } \\
\text { score }\end{array}$ \\
$\begin{array}{l}\text { Vignette identification (major depressive } \\
\text { disorder) }\end{array}$ & 2 \\
\hline $\begin{array}{l}\text { Vignette identification (generalised } \\
\text { anxiety disorder) }\end{array}$ & 2 \\
\hline Perception of persons with mental illness & 7 \\
\hline Purpose of psychiatric medication & 4 \\
\hline Adverse effects of psychiatric medication & 4 \\
\hline Knowledge of psychiatric referral & 3 \\
\hline
\end{tabular}

$\mathrm{p}<0.001)$. Fewer oncology outpatients than controls were employed $(p=0.004)$. Those with primary and secondary education had significantly lower MHL scores than those with university education $(\mathrm{p}=0.001)$. Oncology outpatients

Table 2. Characteristics of participants.

\begin{tabular}{|c|c|c|c|}
\hline & $\begin{array}{c}\text { Oncology } \\
\text { outpatients } \\
(\mathbf{n}=89)^{*}\end{array}$ & $\begin{array}{l}\text { Controls } \\
(n=61)^{*}\end{array}$ & $\begin{array}{c}\mathbf{p} \\
\text { Value }\end{array}$ \\
\hline Male & $49(55.1)$ & $32(52.5)$ & 0.754 \\
\hline Age, $y$ & $51.9 \pm 12.6$ & $44.8 \pm 12.5$ & 0.001 \\
\hline Ethnicity & & & 0.360 \\
\hline Chinese & $70(78.7)$ & $51(83.6)$ & \\
\hline Malay & 13 (14.6) & $3(4.9)$ & \\
\hline Indian & $3(3.4)$ & $3(4.9)$ & \\
\hline Others & $1(1.1)$ & $1(1.6)$ & \\
\hline Foreign-born & $2(2.2)$ & $3(4.9)$ & \\
\hline Education level & & & 0.001 \\
\hline $\begin{array}{l}\text { No formal } \\
\text { education }\end{array}$ & $0(0)$ & $0(0)$ & \\
\hline Primary & $17(19.1)$ & $3(4.9)$ & \\
\hline $\begin{array}{l}\text { Secondary/ } \\
\text { vocational }\end{array}$ & $47(52.8)$ & $23(37.7)$ & \\
\hline $\begin{array}{l}\text { Junior college/ } \\
\text { polytechnic }\end{array}$ & $9(10.1)$ & $18(29.5)$ & \\
\hline Tertiary & $16(18.0)$ & $17(27.9)$ & \\
\hline Employment status & & & 0.004 \\
\hline Employed & $49(55.7)$ & $47(77.0)$ & \\
\hline Unemployed & $11(12.5)$ & $0(0)$ & \\
\hline $\begin{array}{l}\text { Not in labour } \\
\text { force }\end{array}$ & $28(31.8)$ & $14(23.0)$ & \\
\hline Marital status & & & 0.209 \\
\hline Never married & $13(14.6)$ & $15(24.6)$ & \\
\hline Married & $63(70.8)$ & $42(68.9)$ & \\
\hline $\begin{array}{l}\text { Divorced or } \\
\text { separated }\end{array}$ & $11(12.4)$ & $4(6.6)$ & \\
\hline Widowed & $2(2.2)$ & $0(0)$ & \\
\hline Religion & & & 0.392 \\
\hline Christianity & $17(19.1)$ & $20(32.8)$ & \\
\hline Muslim & $14(15.7)$ & $6(9.8)$ & \\
\hline $\begin{array}{l}\text { Buddhist or } \\
\text { Taoist }\end{array}$ & $39(43.8)$ & $23(37.7)$ & \\
\hline Hindu & $2(2.2)$ & $1(1.6)$ & \\
\hline No religion & $17(19.1)$ & $11(18.0)$ & \\
\hline $\begin{array}{l}\text { Hospital Anxiety } \\
\text { and Depression } \\
\text { Scale score }\end{array}$ & & & \\
\hline $\begin{array}{l}\text { Scale score } \\
\text { Anxiety }(>8)\end{array}$ & $12(13.5)$ & $6(9.8)$ & 0.5 \\
\hline Depression $(>10)$ & $2(2.2)$ & $1(1.6)$ & $>0.99$ \\
\hline
\end{tabular}

Data are presented as mean \pm standard deviation or no. (\%) of participants 
Table 3. Mental health literacy of oncology outpatients and controls.

\begin{tabular}{|lccc|}
\hline Mental health literacy & $\begin{array}{c}\text { Oncology outpatients } \\
(\mathbf{n = ~ 8 9})^{*}\end{array}$ & $\begin{array}{c}\text { Controls } \\
(\mathbf{n = 6 1})^{*}\end{array}$ & p Value \\
\hline Vignette identification (major depressive disorder) & $0.78 \pm 0.81$ & $1.00 \pm 0.82$ & 0.095 \\
\hline Vignette identification (generalised anxiety disorder) & $1.00 \pm 0.83$ & $0.98 \pm 0.74$ & 0.818 \\
\hline Perception of persons with mental illness & $1.36 \pm 1.35$ & $1.48 \pm 1.29$ & 0.624 \\
\hline Purpose of psychiatric medication & $1.63 \pm 1.27$ & $2.07 \pm 1.24$ & 0.072 \\
\hline Adverse effects of psychiatric medication & $1.53 \pm 1.54$ & $1.77 \pm 1.56$ & 0.348 \\
\hline Knowledge of psychiatric referral & $1.65 \pm 0.92$ & $1.84 \pm 0.78$ & 0.336 \\
\hline Total score & $7.94 \pm 3.91$ & $9.13 \pm 3.11$ & 0.102 \\
\hline
\end{tabular}

Data are presented as mean \pm standard deviation or no. (\%) of participants

and controls were comparable in terms of levels of anxiety $(13.5 \%$ vs $9.8 \%, \mathrm{p}=0.5)$ and depressive symptoms $(2.2 \%$ vs $1.6 \%, \mathrm{p}>0.99$ ).

With regard to MHL, oncology outpatients and controls were comparable in terms of identifying major depressive disorder $(0.78$ vs $1.00, \mathrm{p}=0.095)$ and generalised anxiety disorder (1.00 vs $0.98, \mathrm{p}=0.818)$ and total MHL score (7.94 vs $9.13, \mathrm{p}=0.102)$ [Table 3].

\section{Discussion}

Our data suggest a strong association between education level and MHL: those with higher education were more likely to possess psychological mindedness and better help-seeking knowledge. In addition, the prevalence of depressive and anxiety symptoms in our oncology outpatients (13.5\% and 2.2\%, respectively) was much lower than that in hospitalised patients with cancer in a local study, ${ }^{4}$ probably because our study cohort was recruited from an outpatient setting. Our study cohort had better physical health and functioning, with all participants having Eastern Cooperative Oncology Group Performance Status of 0 or 1. However, hospitalised patients tend to be more physically ill, with a higher prevalence of psychiatric disorders as a consequence of their illnesses. ${ }^{21}$

Our oncology outpatients had poorer understanding of psychological problems (lower MHL scores) than controls had. This finding is consistent with that reported in Japanese patients with cancer. ${ }^{22}$ Patients with cancer may have difficulty identifying psychological distress, as certain psychiatric symptoms overlap with cancer symptoms. They may incorrectly attribute symptoms of psychological distress to symptoms of medical conditions. For instance, depressive symptoms such as insomnia, poor appetite, weight loss, and fatigue could be mistaken for symptoms of cancer or adverse effects of treatment. Inadequate MHL may result in failure to recognise the need for psychiatric treatment.
In addition, stigma associated with psychiatric illness may hinder treatment seeking. ${ }^{23-25}$ Non-detection of psychiatric symptoms by oncologists may also lead to failure to refer patients for psychiatric consultation and treatment and potentially reduced quality of life and poorer cancer prognosis.$^{26}$ Depression has been identified as a risk factor for disease recurrence and decreased overall survival in patients with cancer. ${ }^{27,28}$

Low educational level is associated with poor understanding of mental disorders. The presence of mental disorders and contact with psychiatric services do not result in improved MHL. ${ }^{20}$ This suggests that further effort is needed to educate the general public on common mental disorders and referral pathways. It appears that campaigns and public talks used to improve MHL and raise awareness in the community have not been effective. Perhaps these efforts targeted better educated people, or those with lower educational levels were unable to access or understand them. We may consider simplifying educational materials and expanding outreach services to cater to the underserved. Oncologists should encourage patients to discuss their emotional distress. Regular communication and exploration of psychological difficulties related to diagnosis, treatment, and psychosocial sequelae are especially important. Oncologists should work closely with mental health professionals on referral of patients for psychiatric treatment if needed.

Our study has several limitations. There is a lack of a standard measure of MHL in general and a lack of criteria for what constitutes high or low MHL. This greatly limits comparisons between studies. However, MHL is culture-specific, and its assessment in our study was based on previously published standards. In addition, the small sample size and the significant difference in patient age between the two groups may have resulted in the lack of statistical significance in certain findings. The oncology outpatients were heterogeneous and comprised those with different cancer diagnoses at various stages of treatment, 
with a myriad of possible prognoses. We were unable to adjust for potential confounders because of the small sample size. Our oncology outpatients tended to have lower distress levels given their higher levels of physical functioning and may have been psychologically well enough not to require psychiatric attention despite having experienced marginally more psychiatric symptoms than controls. Conversely, some oncology outpatients may have declined radiotherapy because of distress and hence were not recruited to the study.

\section{Conclusion}

MHL is comparable between oncology outpatients and controls and is positively associated with education levels. Psychoeducation should entail acknowledging psychological distress, informing overlaps between psychiatric and physical symptoms, and encouraging help seeking.

\section{Acknowledgments}

This study was supported by the Lee Foundation. The authors wish to thank Ms Kwok Li-Lian for providing preliminary statistical assistance, the faculty and staff of the Department of Radiation Oncology, the National Cancer Centre Singapore, and all physicians who provided care for the patients.

\section{References}

1. Chiou Y, Chiu NM, Wang LJ, Li SH, Lee CY, Wu MK, et al. Prevalence and related factors of psychological distress among cancer inpatients using routine Distress Thermometer and Chinese Health Questionnaire screening. Neuropsychiatr Dis Treat 2016;12:2765-73. Crossref

2. Mehnert A, Brähler E, Faller H, Härter M, Keller M, Schulz H, et al. Four-week prevalence of mental disorders in patients with cancer across major tumor entities. J Clin Oncol 2014;32:3540-6. Crossref

3. Mitchell A, Chan M, Bhatti H, Halton M, Grassi L, Johansen C, et al. Prevalence of depression, anxiety, and adjustment disorder in oncological, haematological, and palliative-care settings: a meta-analysis of 94 interview-based studies. Lancet Oncol 2011;12:160-74. Crossref

4. Tan SM, Beck KR, Li H, Lim EC, Krishna LK. Depression and anxiety in cancer patients in a Tertiary General Hospital in Singapore. Asian J Psychiatr 2014;8:33-7. Crossref

5. Ell K, Sanchez K, Vourlekis B, Lee PJ, Dwight-Johnson M, Lagomasino $\mathrm{I}$, et al. Depression, correlates of depression, and receipt of depression care among low-income women with breast or gynecologic cancer. J Clin Oncol 2005;23:3052-60. Crossref

6. Nakash O, Levav I, Aguilar-Gaxiola S, Alonso J, Andrade LH, Angermeyer MC, et al. Comorbidity of common mental disorders with cancer and their treatment gap: findings from the World Mental Health Surveys. Psychooncology 2014;23:40-51. Crossref

7. Chong SA, Abdin E, Vaingankar JA, Heng D, Sherbourne C, Yap M, et al. A population-based survey of mental disorders in Singapore. Ann Acad Med Singapore 2012;41:49-66.

8. Steele L, Dewa C, Lee K. Socioeconomic status and self-reported barriers to mental health service use. Can J Psychiatry 2007;52:2016. Crossref

9. Jorm AF. Mental health literacy. Public knowledge and beliefs about mental disorders. Br J Psychiatry 2000;177:396-401. Crossref

10. Angermeyer MC, Dietrich S. Public beliefs about and attitudes towards people with mental illness: a review of population studies. Acta Psychiatr Scand 2006;113:163-79. Crossref

11. Angermeyer MC, Matschinger H. The stereotype of schizophrenia and its impact on discrimination against people with schizophrenia: results from a representative survey in Germany. Schizophr Bull 2004;30:1049-61. Crossref

12. Lauber C, Nordt C, Falcato L, Rössler W. Do people recognise mental illness? Factors influencing mental health literacy. Eur Arch Psychiatry Clin Neurosci 2003;253:248-51. Crossref

13. Rüsch N, Evans-Lacko S, Henderson C, Flach C, Thornicroft G. Knowledge and attitudes as predictors of intentions to seek help for and disclose a mental illness. Psychiatr Serv 2011;62:675-8. Crossref

14. ten Have M, de Graaf R, Ormel J, Vilagut G, Kovess V, Alonso J, et al. Are attitudes towards mental health help-seeking associated with service use? Results from the European Study of Epidemiology of Mental Disorders. Soc Psychiatry Psychiatr Epidemiol 2010;45:15363. Crossref

15. Baillargeon J, Kuo YF, Lin YL, Raji MA, Singh A, Goodwin JS. Effect of mental disorders on diagnosis, treatment, and survival of older adults with colon cancer. J Am Geriatr Soc 2011;59:1268-73. Crossref

16. Ng TP, Fones CS, Kua EH. Preference, need and utilization of mental health services, Singapore National Mental Health Survey. Aust N Z J Psychiatry 2003;37:613-9. Crossref

17. Oken MM, Creech RH, Tormey DC, Horton J, Davis TE, McFadden ET, et al. Toxicity and response criteria of the Eastern Cooperative Oncology Group. Am J Clin Oncol 1982;5:649-55. Crossref

18. Zigmond AS, Snaith RP. The hospital anxiety and depression scale. Acta Psychiatr Scand 1983;67:361-70. Crossref

19. Beck KR, Tan SM, Lum SS, Lim LE, Krishna LK. Validation of the emotion thermometers and hospital anxiety and depression scales in Singapore: screening cancer patients for distress, anxiety and depression. Asia Pac J Clin Oncol 2016;12:e241-9. Crossref

20. Lim L, Goh J, Chan YH, Poon SH. Mental health literacy and the belief in the supernatural. Open J Psychiatry 2015;5:334-41. Crossref

21. Harter M, Reuter K, Aschenbrenner A, Schretzmann B, Marschner $\mathrm{N}$, Hasenburg A, et al. Psychiatric disorders and associated factors in cancer: results of an interview study with patients in inpatient, rehabilitation and outpatient treatment. Eur J Cancer 2001;37:138593. Crossref

22. Okuyama T, Nakane Y, Endo C, Seto T, Kato M, Seki N, et al. Mental health literacy in Japanese cancer patients: ability to recognize depression and preferences of treatments: comparison with Japanese lay public. Psychooncology 2007;16:834-42. Crossref

23. Cheung YT, Ong YY, Ng T, Tan YP, Fan G, Chan CW, et al. Assessment of mental health literacy in patients with breast cancer. J Oncol Pharm Pract 2016;22:437-47. Crossref

24. Matthews AK, Corrigan PW, Rutherford JL. Mental illness stigma as a barrier to psychosocial services for cancer patients. J Natl Compr Canc Netw 2003;1:375-9. Crossref

25. Meacham E, Orem J, Nakigudde G, Zujewski JA, Rao D. Exploring stigma as a barrier to cancer service engagement with breast cancer survivors in Kampala, Uganda. Psychooncology 2016;25:120611. Crossref

26. Reich M, Lesur A, Perdrizet-Chevallier C. Depression, quality of life and breast cancer: a review of the literature. Breast Cancer Res Treat 2008;110:9-17. Crossref

27. Satin JR, Linden W, Phillips MJ. Depression as a predictor of disease progression and mortality in cancer patients: a meta-analysis. Cancer 2009;115:5349-61. Crossref

28. Antoni MH, Lutgendorf SK, Cole SW, Dhabhar FS, Sephton SE, McDonald PG, et al. The influence of bio-behavioural factors on tumour biology: pathways and mechanisms. Nat Rev Cancer 2006;6:240-8. Crossref 